\title{
Erratum
}

\section{Lewis Acid Promoted Oxidative Rearrangement of Tertiary Allylic Alcohols with the PhIO/TEMPO System}

Jean-Michel Vatèle* Synlett 2008, 1785.

In the advance online (e-First) publication of this manuscript, the structures shown in Table 2, entry 10 were incorrect. These have been corrected for both the print and the current online versions. 